Article publié par le Laboratoire de Construction en Béton de l'EPFL

Paper published by the Structural Concrete Laboratory of EPFL

\begin{tabular}{|l|l|}
\hline Title: & Derivation of the $\sigma-\mathrm{w}$ relationship for SFRC from prism bending tests \\
\hline Authors: & Amin A., Foster S. J., Muttoni A. \\
\hline Published in: & Structural Concrete \\
\hline DOI & $10.1002 /$ suco.201400018 \\
\hline Pages: & pp. $93-105$ \\
\hline Year of publication: & 2015 \\
\hline Type of publication: & Peer reviewed journal article \\
\hline
\end{tabular}

Please quote as:

Amin A., Foster S. J., Muttoni A., Derivation of the $\sigma$-w relationship for SFRC

from prism bending tests, Structural Concrete, 2015, pp. 93-105. 


\section{Derivation of the $\sigma-w$ relationship for SFRC from prism bending tests}

The material characterization of steel fibre-reinforced concrete (SFRC), which is required for its implementation in design codes, should be based on nominal properties that describe its postcracking strength in tension. In the case of brittle and quasi-brittle materials, such as concrete, the tensile parameters are often derived indirectly. However, for materials with more ductility, such as SFRC, there is conjecture as to whether or not an indirect measure may be used to establish the stress versus crack opening displacement relationship, such as the use of a three- or fourpoint prism test combined with an inverse analysis. In this paper a simple and efficient inverse analysis technique is developed and shown to compare well with data obtained from direct tension tests. Furthermore, the methodology proposed by the fib Model Code for Concrete Structures 2010 has been investigated and recommendations made to improve its accuracy.

Keywords: steel fibre, concrete, inverse analysis, bending, uniaxial tension

\section{Introduction}

Research in steel fibre-reinforced concrete has a history of about 50 years [1] and its adoption in practice is developing. It is well established that the strength of unreinforced concrete in tension reduces quickly to zero after cracking. In steel fibre-reinforced concrete (SFRC) the fibres are capable of bridging cracks and transmitting tensile force across them to enhance the post-cracking tensile behaviour.

One limitation in developing rational design models for SFRC in members and structures is the complexity of the test needed to characterize the fundamental tensile strength properties of the material, i.e. determining its post-cracking, or residual, tensile strength. Prior to cracking, the characteristic behaviour of SFRC in tension is typically represented by its stress-strain response. After cracking, behaviour is described by the stress versus crack opening displacement $(\sigma-w)$ relationship (Fig. 1). The $\sigma-w$ response can be obtained through a uniaxial tension test or possibly by an indirect method using three- or fourpoint bending tests on prism beam specimens in conjunction with an inverse analysis that assumes some prede-

\footnotetext{
* Corresponding author: s.foster@unsw.edu.au
}

fined deterministic relationship. This is summarized in Fig. 2, where CMOD is the crack mouth opening displacement as measured across the notch at the extreme tensile fibre in a flexural prism test.

Although a direct tensile test is the most reliable method for determining the residual (post-cracking) properties of SFRC [2-4], it is expensive. It requires specialized testing machines and can be time-consuming in its preparation. For this reason, extensive efforts have been made to find a reliable model for obtaining the post-cracking behaviour based on an inverse analysis of data obtained from either notched or unnotched prism bending tests [5-8]. However, although this methodology has been incorporated in the fib Model Code for Concrete Structures 2010 [8-10], the test data available at the time for full validation was somewhat limited [11].

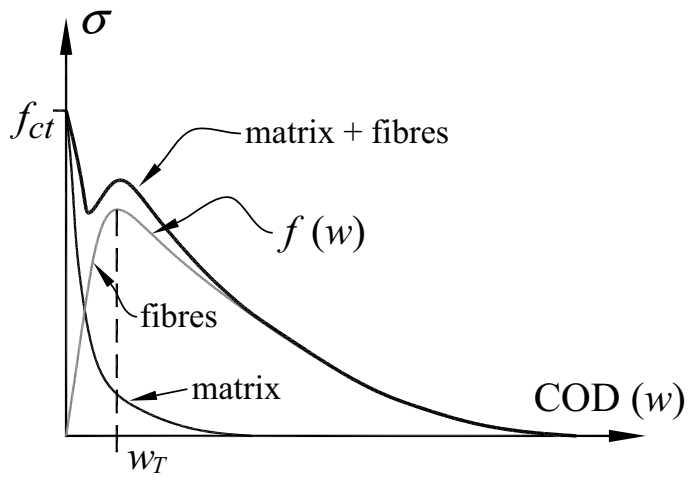

Fig. 1. Stress versus crack COD $(w)$ for SFRC

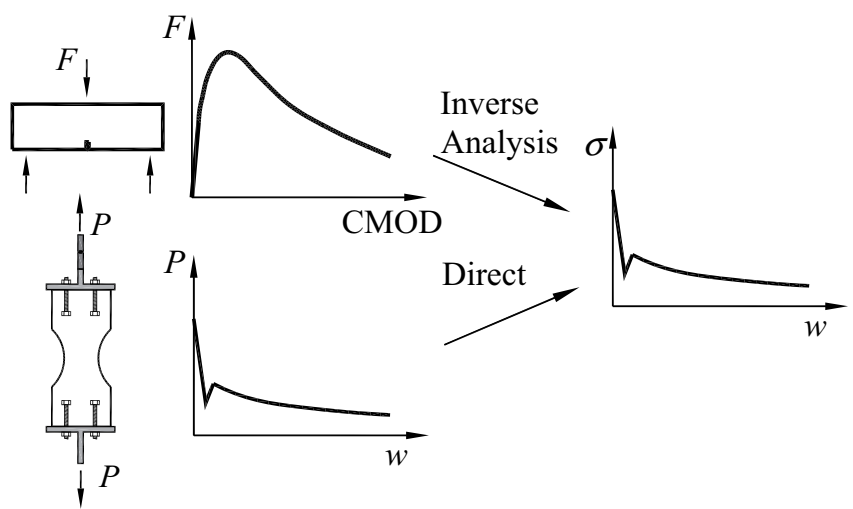

Fig. 2. Approaches to determine the tensile properties of SFRC 
In this paper a physically based model is developed to predict the tensile response of strain-softening SFRC from prism bending tests. To validate the model, tests were conducted for six series of matched uniaxial tension and prism bending tests for various fibre types and ratios, and for different flexural prism testing arrangements. The results of these matched tests are reported here and the model predictions presented. Finally, based on the model described, a $\sigma-w$ relationship for the post-cracking residual tensile strength of SFRC for use in design is proposed. The material law is compared with test data collected in this study and elsewhere, also with predictions obtained using the fib Model Code 2010 approach, and conclusions are drawn.

\section{The $\sigma$ - $w$ model for SFRC}

\subsection{Determination of contribution of fibres to strength of SFRC}

Fig. 3a shows the cross-section of an SFRC prism cracked in bending, where $D$ is the total depth of the prism, $h_{\mathrm{sp}}$ the depth minus the notch depth, $d_{n}$ the depth from extreme compressive fibre to neutral axis and $b$ the width of the prism. On the compression side (Fig. 3b), the neutral axis rises in the section as the crack opens; on initial cracking the stress block is linear, becoming non-linear as CMOD increases. The lever arm $z$ (Fig. 4) is insensitive to the shape of the compressive stress block, however, and it is sufficiently accurate to assume the stress block to be linear throughout the analysis.

For a small length on the tension side of the neutral axis (Fig. 3b), the concrete is uncracked and carries tension. At greater distances from the neutral axis, the concrete is cracked and the steel fibres carry a tensile stress $f(w)$ that corresponds to a direct tensile stress for a crack opening $w$ at the level in the section under consideration. Assuming that i) the tensile component of the uncracked concrete can be ignored, ii) the crack width is directly pro-

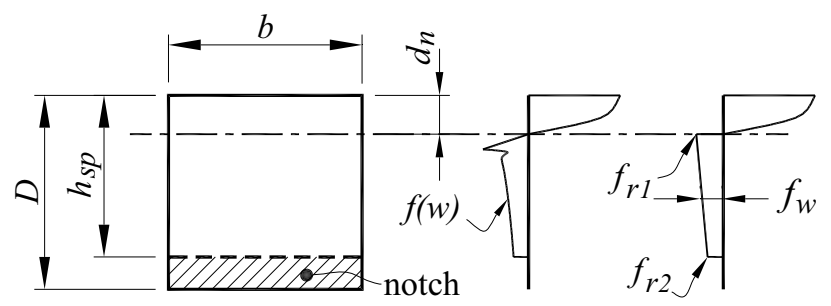

(a) Section

(b) Stresses at crack

(c) Simplified Model

Fig. 3. Model for inverse analysis of $\sigma-w$ curve from prism bending tests

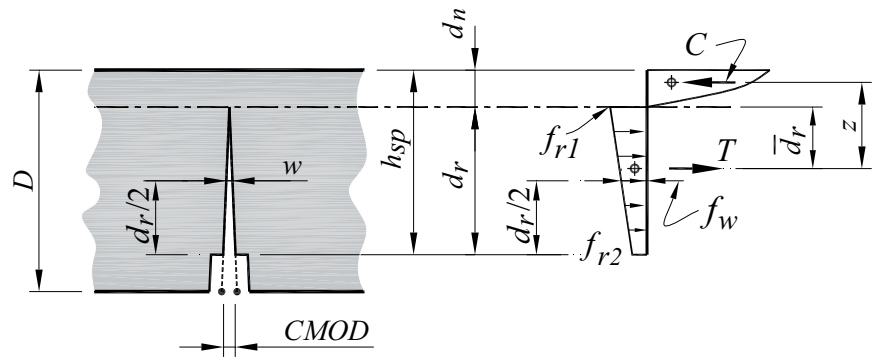

Fig. 4. Stresses at cracked section for SFRC prism in bending portional to the distance from the neutral axis (rigid body rotation) and iii) the $\sigma-w$ relationship is approximately linear over the range of crack widths of interest $[12,13]$, the tensile stress block can be simplified as shown in Fig. 3c. The stress on the $\sigma-w$ curve for the average crack opening displacement (COD) between the root of the notch and the crack tip is denoted as $f_{w}$, and is calculated as follows:

$f_{w}=\left(f_{r 1}+f_{r 2}\right) / 2$

where $f_{\mathrm{r} 1}$ is the stress for $w=0$ and $f_{r 2}$ is the stress at the notch root.

From the sectional stress blocks (Fig. 4)

$T=f_{w} d_{r} b$

The centroid of the tensile stress block measured from the neutral axis $\bar{d}_{r}$ is

$\bar{d}_{r}=\frac{f_{r 1}+2 f_{r 2}}{6 f_{w}} d_{r}$

and taking $f_{r 1}=f_{w}(1+\alpha)$ and $f_{r 2}=f_{w}(1-\alpha)$, Eq. (3) becomes

$\bar{d}_{r}=\frac{3-\alpha}{6} d_{r}$

The shape of the compressive stress block (Fig. 4) changes from elastic to inelastic and depends on the compressive strength of the concrete and the state of loading. When elastic, the stress block is triangular and its centroid is positioned $0.67 d_{n}$ above the neutral axis (NA). If fully inelastic, then using the parabolic-rectangular stress-block model of fib Model Code 2010 [10], its centroid is $0.60 d_{n}$ above the NA. For the case of the NA located at $0.2 h_{\mathrm{sp}}$, the internal lever arm changes from $0.92 h_{\mathrm{sp}}$ to $0.93 h_{\mathrm{sp}}, \mathrm{a}<1 \%$ difference. In this paper the height of the stress-block centroid above the NA is taken as $0.64 d_{n}$. Thus, from equilibrium $(M=T z)$ we can write

$\frac{F a}{2}=f_{w} d_{r} b\left(0.64 d_{n}+\bar{d}_{r}\right)$

where $F$ is the externally applied force and $a$ is the shear span (see Fig. 5). From geometry

$d_{r}=h_{s p}-d_{n}$

Examination of Eqs. (4) to (6) reveals that we have three independent variables $\left(f_{w}, d_{n}\right.$ and $\left.\alpha\right)$ and two dependent
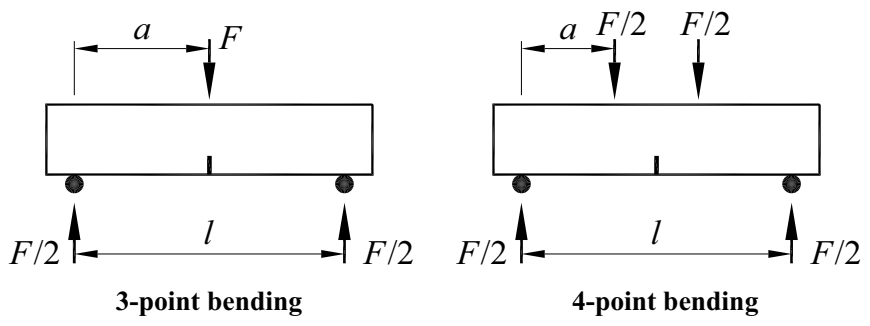

Fig. 5. Forces applied to three-point and four-point bending prism specimens 
variables $\left(d_{r}, \bar{d}_{r}\right)$, with one independent equation (Eq. (5)) to solve. The problem is two-fold indeterminate and the solution thus intractable.

Eq. (5) may be written as

$f_{w}=\frac{k_{1} k_{2} 2 M}{h_{s p}^{2} b}=\frac{k_{1} k_{2} F a}{h_{s p}^{2} b}$

where $k_{1}$ is a function of $d_{n} / h_{s p}$ and $\alpha\left(k_{1} \geq 1\right)$, and can be determined from Eqs. (4) and (5) as

$k_{1}=\frac{3}{[3.9-(0.85+\alpha) \beta] \beta}$

where $\beta=1-d_{n} / h_{s p}$.

Coefficient $k_{2}$ is included in Eq. (7) to account for the influence of the notch on defining the crack path and the resulting influence on the measured tensile strength, as described in [14]. For the case of unnotched specimens, the critical crack will find a path of least resistance and failure occurs at sections where fibre distributions are at their lowest and thus the equivalent fibre dosage at the failure section is less than the average fibre dosage for the specimen. By contrast, in notched specimens the location of the failure plane is predefined by the location of the notch and the fibre volume fraction at the failure section will, on average, equal the supplied fibre dosage for the specimen. To convert the results of notched prism tests to those of unnotched uniaxial tensile tests, the factor $k_{2}=0.82$ is applied, as described in [14, 15].

We shall now look more closely at parameter $\alpha$ and the location of the neutral axis depth $d_{n}$. In Fig. 6 the value of $k_{1}$ is plotted for different values of $d_{n} / h_{s p}$ and varying $\alpha$. The figure shows that over the range of interest $k_{1}$ at $1.2 \pm 20 \%$, is relatively insensitive to the combination of $\alpha$ and $d_{n}$. Hence, the determination of $f_{w}$ is somewhat insensitive to the values selected for $\alpha$ and $d_{n}$. Taking $\alpha=0.2$ and $d_{n}=0.2 h_{s p}$ results in $k_{1}=1.25$ and $k_{1} k_{2} \approx 1$. This is similar to the value determined in $[8,11]$ for the case where $\alpha=0.2$ and $d_{n}=0.2 h_{s p}$ and where the notch effect is ignored (i.e. $k_{2}=1.0$ ).

To determine the crack opening displacement corresponding to the calculated value of $f_{w}$, we assume i) rigid body rotations of the two prism halves centred about the crack tip and ii) failure occurs along a single dominant crack. The COD $(w)$ for our $\sigma-w$ curve is obtained from the measured crack mouth opening displacement (CMOD) as shown in Fig. 4:

$w=\frac{C M O D}{2} \cdot \frac{\left(h_{s p}-d_{n}\right)}{\left(D-d_{n}\right)}$

In Fig. 7 the ratio $w / C M O D$ from Eq. (9) is plotted against the ratio $d_{n} / h_{s p}$ for prisms with $h_{s p} / D=0.83$ (as per EN 14651 [9]) and $h_{s p} / D=0.70$ (as per JCI-S-002 [16]) and normalized against the value calculated for $d_{n}=0$. For the EN 14651 [9] testing configuration, the change in the ratio $w / C M O D$ with $h_{s p} / D=0.83$ is $10 \%$ from the condition soon after cracking (taken at $d_{n} / h_{s p}=0.4$ ) to the time when the neutral axis is high in the section. For the JCIS-002 configuration [16] the change is $17 \%$. Again, the results are somewhat insensitive to the neutral axis depth.

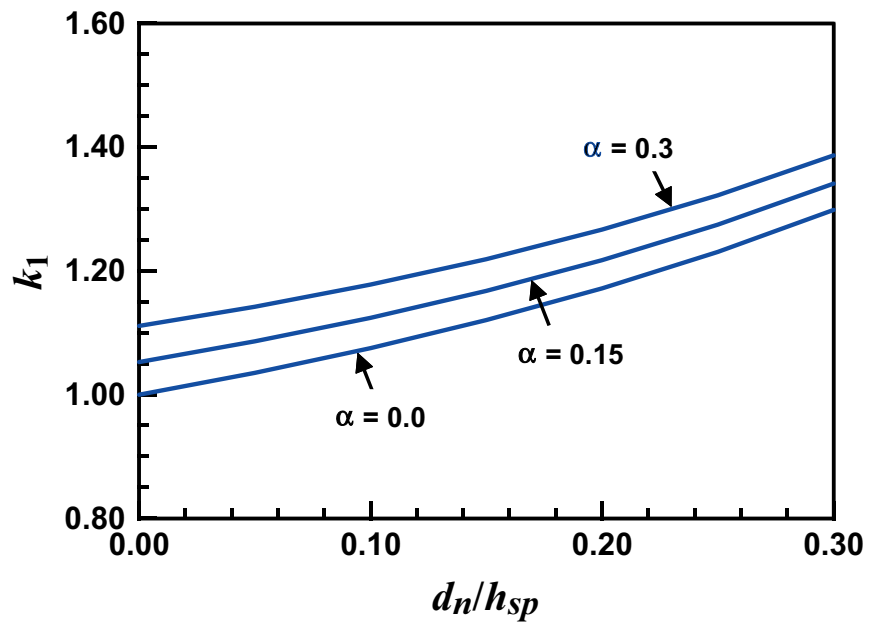

Fig. 6. Ratio of the internal tensile force to the external applied force versus the neutral axis depth ratio $d_{n} / h_{s p}$ for various values of $\alpha$

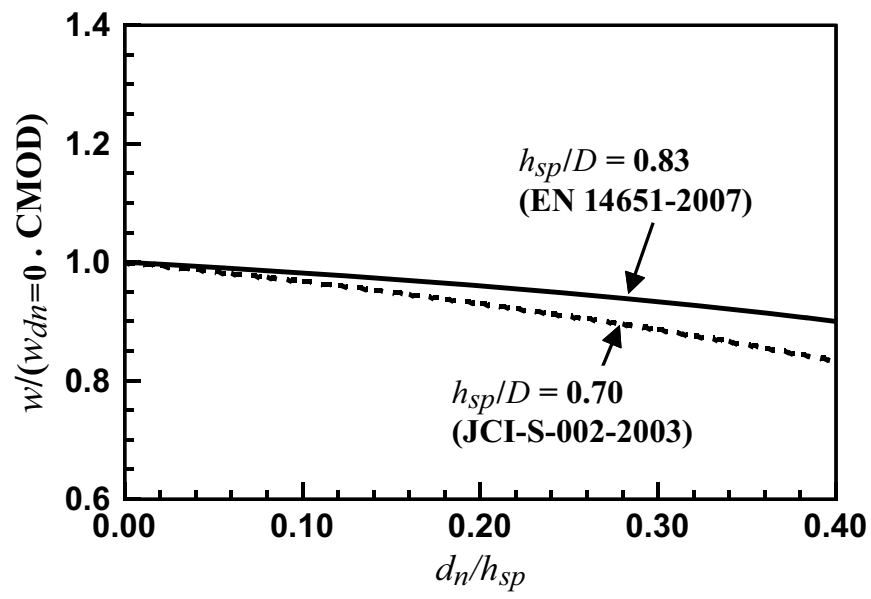

Fig. 7. Ratio of $w / C M O D$ versus $d_{n} / h_{s p}$ for prisms with $h_{s p} / D=0.83$ and $h_{s p} / D=0.70$

For design, an appropriately conservative value is recommended and entering $d_{n}=0.3 h_{s p}$ in Eq. (9) results in

$w=\frac{C M O D \times 0.35 h_{s p}}{D-0.3 h_{s p}}$

\subsection{Stress-COD relationship for SFRC}

The strength of the composite for a given COD can be determined from

$\sigma(w)=\sigma_{c}(w)+\sigma_{f}(w)$

where $\sigma_{c}(w)$ is the concrete component for a given COD, including any beneficial coupling effect that the fibres might have on the matrix, and $\sigma_{f}(w)$ is the nominal stress carried by the fibres. In the prism tests, during the early stages of the test post-cracking, consideration of the matrix component is significant when interpreting the resulting moment versus CMOD response. At later stages of the test, the influence of the matrix component is less significant and may be obtained from Eq. (11), taking $\sigma_{f}(w)=f_{w}$ for the COD $(w)$ given by Eq. (10). This response is depicted in Fig. 8, with a transition zone between the cracking point $C M O D_{0}$ and a point $C M O D_{T}$ where the influence of 


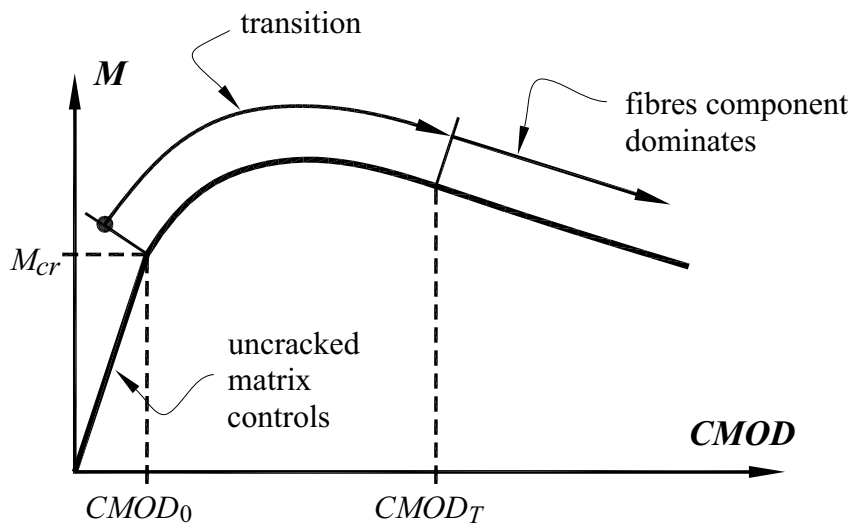

Fig. 8. Simplified approach for the transition in the moment-CMOD response of the prism test being influenced by the uncracked concrete component to the stress block to the point where the uncracked concrete component is insignificant

the uncracked concrete on the moment-CMOD response may be considered to be insignificant.

Voo and Foster [17] and Foster et al. [18] observed that the take-up, or engagement, of fibres is delayed from the initial point of cracking, with the length of the delay dependent on the angle of a fibre with respect to the cracking plane, and with the complete response determined by integrating the individual fibre responses. The result of this is a progressive take-up of the fibres component from the initial point of cracking to a peak, as shown in Fig. 1. To develop the first part of the curve, we take the fibres component to be

$\sigma_{f}(w)=\zeta(w) f_{w}$

where $f_{w}$ is obtained from Eq. (9) and $\zeta(w)$ is a transition function. In this paper we adopt an elliptical transition function:

$\zeta(w)= \begin{cases}\sqrt{1-\frac{\left(w_{T}-w\right)^{2}}{w_{T}^{2}}} & \text { if } w<w_{T} \\ 1 & \text { if } w \geq w_{T}\end{cases}$

where $w_{T}$ (see Fig. 1) is the point on the $\sigma-w$ curve where the fibres have achieved their maximum effectiveness. It should be noted that this transition only influences the initial part of the response after cracking and is not overly significant in the development of a simple design ap- proach for determining the residual direct tensile strength from prism bending tests.

For plain concrete, the tensile softening stress can be taken as [17, 19-21]

$\sigma_{c}(w)=c_{1} f_{c t} e^{-c_{2} w}$

where $f_{c t}$ is the tensile strength of the concrete without fibre reinforcement and $c_{1}$ and $c_{2}$ are coefficients. Coefficient $c_{1}$ accounts for any beneficial effect of the fibres on the peak matrix strength and $c_{2}$ is a factor that controls the steepness of the descending branch and is influenced by the volume of fibres and the cementitious matrix composition. For Mode I fracture, Voo and Foster [17, 19, 22] adopted $c_{1}$ as unity. For $c_{2}, N g$ et al. [23] proposed the following:

$c_{2}=30 /\left(1+100 \rho_{\mathrm{f}}\right)$

... for mortar and concrete with $a_{\mathrm{g}} \leq 10 \mathrm{~mm}$

$c_{2}=20 /\left(1+100 \rho_{\mathrm{f}}\right)$

... for concrete with $a_{\mathrm{g}}>10 \mathrm{~mm}$

where $a_{\mathrm{g}}$ is the maximum size of the aggregate particles.

\section{Experimental validation}

Specimens were cast for direct tension tests and notched prism tests using six SFRC mix designs. The SFRC mixes were fabricated using two types of commercially available steel fibres: end-hooked (EH) Dramix ${ }^{\circledR}$ RC-65/35-BN cold-drawn wire fibres and OL13/0.20 straight (S) highcarbon steel fibres, both manufactured by Bekaert. The $\mathrm{EH}$ fibres were $0.55 \mathrm{~mm}$ in diameter, $35 \mathrm{~mm}$ long and had a tensile strength of $1340 \mathrm{MPa}$. The S fibres were $0.2 \mathrm{~mm}$ in diameter, $13 \mathrm{~mm}$ long and had a tensile strength $>1800 \mathrm{MPa}$.

The tests are categorized in two series: series AM and series DA. The fibre volumetric dosages adopted in this study were $0.4,0.5,0.8$ and $1.0 \%$ for the EH fibres and 0.5 and $1.0 \%$ for the S fibres. The aggregate used was basalt with a maximum particle size of $10 \mathrm{~mm}$.

The compressive strength characteristics of the concrete used in the study were determined from $100 \mathrm{~mm}$ diameter $\times 200 \mathrm{~mm}$ high cylinders tested after 28 days of moist curing at $23{ }^{\circ} \mathrm{C}$; the results are summarized in Table 1 . The mean compressive strength $f_{c m}$ was determined from three cylinders tested with load control at a rate of $20 \mathrm{MPa} / \mathrm{min}$, as per AS1012.9 [24]. The modulus of

Table 1. Mechanical properties of SFRC mixes

\begin{tabular}{llllllll}
\hline Mix & Fibre type & Fibre vol. $(\%)$ & $\boldsymbol{f}_{\boldsymbol{c m}}(\mathbf{M P a})$ & $\boldsymbol{l}_{\boldsymbol{f}}(\mathbf{m m})$ & $\boldsymbol{d}_{\boldsymbol{f}}(\mathbf{m m})$ & $\boldsymbol{E}_{\boldsymbol{o}}(\mathbf{G P a})$ & $\boldsymbol{f}_{\boldsymbol{c t}}(\mathbf{M P a})$ \\
\hline DA-0.5-EH & end-hooked & 0.5 & 56.2 & 35 & 0.55 & 33.0 & 3.85 \\
\hline DA-1.0-EH & end-hooked & 1.0 & 60.1 & 35 & 0.55 & 31.5 & 3.92 \\
\hline DA-0.5-S & straight & 0.5 & 63.7 & 13 & 0.20 & 34.7 & 4.03 \\
\hline DA-1.0-S & straight & 1.0 & 63.0 & 13 & 0.20 & 35.8 & 4.30 \\
\hline AM-0.4-EH & end-hooked & 0.4 & 61.3 & 35 & 0.55 & 33.5 & 4.15 \\
\hline AM-0.8-EH & end-hooked & 0.8 & 63.8 & 35 & 0.55 & 34.0 & 4.52 \\
\hline
\end{tabular}


elasticity $E_{o}$ was obtained in accordance with AS1012.17 [25]. The tensile strength of the matrix $f_{c t}$ was obtained from dog-bone tests (described below).

The uniaxial tensile test was conducted on hour glass-shaped "dog-bone" specimens with the shape introduced by van Vliet [26]. Fig. 9a shows the specimen size and test setup details adopted in this study. Four specimens were cast and tested for each of the DA mixes; six specimens were cast and tested for each of the AM mixes. The specimens were filled using the procedure outlined in [9], i.e. the centre portion of the mould was filled to approx. $90 \%$ of the height of the specimen, which was then followed by pouring of the ends. The moulds were compacted using a vibrating table.

The dog-bone specimens were tested in an Instron servo-hydraulic universal testing machine (UTM). Prior to
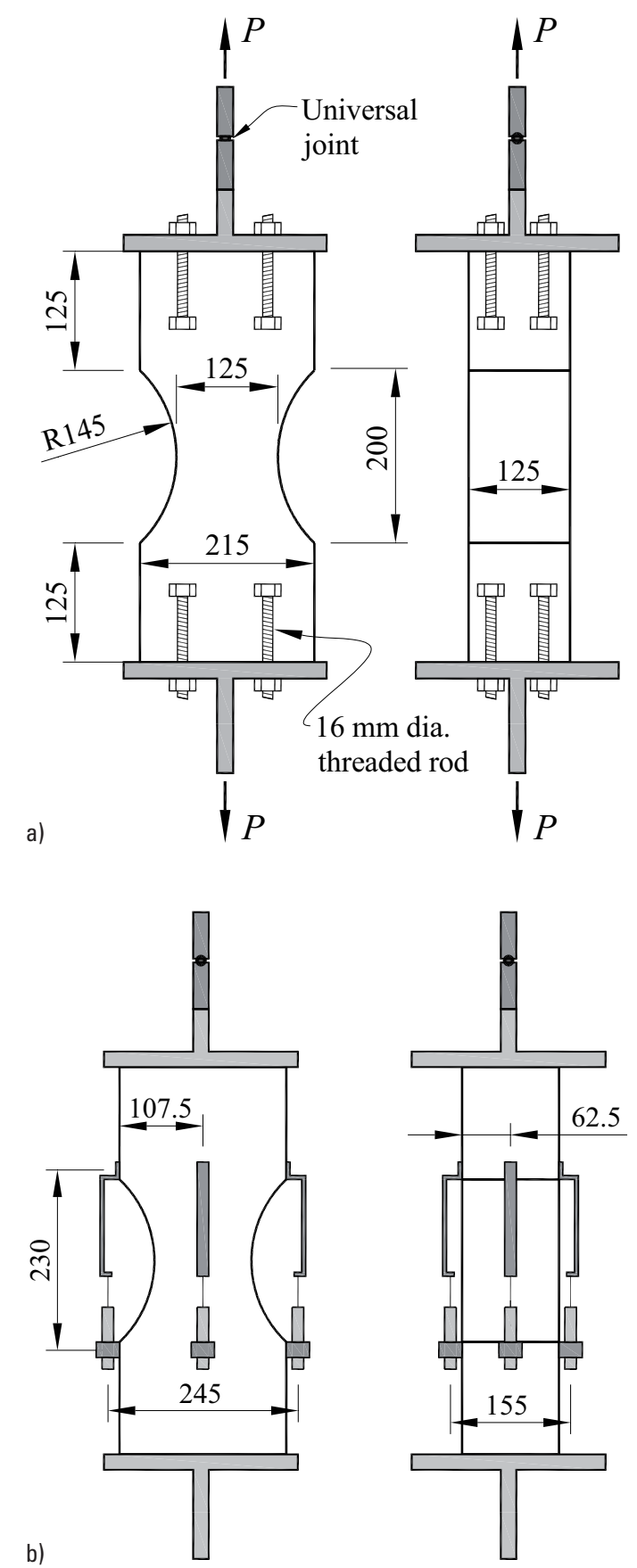

Fig. 9. Details of uniaxial tension test specimens: a) specimen dimensions, b) displacement transducer locations casting, four $16 \mathrm{~mm}$ threaded rods were embedded $100 \mathrm{~mm}$ in each end of the sample. Upon testing, the specimen was bolted to end plates and connected to the UTM. One end of the test arrangement was connected to the testing machine through a universal joint, the other through a fixed platen. This arrangement was used to ensure that no stresses were transferred to the specimen during the connection to the UTM. To measure the COD, two LVDTs were attached to the north and south faces and two LSCTs on the east and west faces of the specimen. The gauges were centred on the specimen and had gauge lengths of $230 \mathrm{~mm}$ (Fig. 9b). Loading was applied using displacement control, initially at a rate of $0.12 \mathrm{~mm} / \mathrm{min}$, until the formation of the dominant crack. After cracking, the rate was increased to $0.2 \mathrm{~mm} / \mathrm{min}$, with additional rate increases introduced as the test progressed.

The notched three-point beam tests were performed on two different prism sizes for the DA series: $150 \times 150 \times$ $500 \mathrm{~mm}$ long prisms, with a notch depth of $45 \mathrm{~mm}$ and spanning $456 \mathrm{~mm}$, and $100 \times 100 \times 500 \mathrm{~mm}$ long prisms, with a notch depth of $30 \mathrm{~mm}$ and spanning $400 \mathrm{~mm}$ (as per [16]). For the AM series, the prism beam tests were performed on $150 \times 150 \times 600 \mathrm{~mm}$ long prisms, with a notch depth of $25 \mathrm{~mm}$ and spanning $500 \mathrm{~mm}$, and tested to EN 14651 [9]. The notches were cut with a diamondtipped saw-blade. In the DA series of tests, two prism tests were carried out for each specimen size and test configuration; for the AM series of tests, six specimens were cast and tested for each fibre dosage.

The prismatic specimens were tested using a closed loop test system by attaching a clip gauge to the underside of the beam at the notch to measure and control the CMOD at the extreme tensile fibre. The test was operated such that the CMOD increased at a constant rate of $0.05 \mathrm{~mm} / \mathrm{min}$ for the first $2 \mathrm{~min}$ and then increased to $0.2 \mathrm{~mm} / \mathrm{min}$ until the CMOD reached $4 \mathrm{~mm}$ for the DA series of tests and $13 \mathrm{~mm}$ for the AM series of tests.

\section{$4 \quad$ Test results}

The experimental results for the uniaxial tests are presented in Fig. 10; the points plotted on the axes of the figures are the tensile strengths of the matrix, with the averages for each series given in Table 1. The fracture processes of all the specimens consisted of three key stages. The first stage involved the formation of meso or hairline cracks $<0.05 \mathrm{~mm}$ wide; once initiated, the crack propagated along the weakest cross-section along a surface. At this stage the peak stress had been reached. This was quickly followed by a sharp reduction in load, coinciding with a significant opening of the crack, as the elastic strain energy stored in the specimen and testing rig was recovered. Thus, no displacement data is available between the peak load and that corresponding to the stabilized crack. It was observed, however, that the initial load after cracking had dropped below that of the peak residual strength of the SFRC specimens with low fibre dosages. The results are presented in Table 2 to highlight the in-plane and out-ofplane rotations of the uniaxial specimens at an average COD equal to $1.5 \mathrm{~mm}$. After the crack had stabilized, the load again increased as the fibres became engaged. The long tail of each curve reflects the progressively smooth 

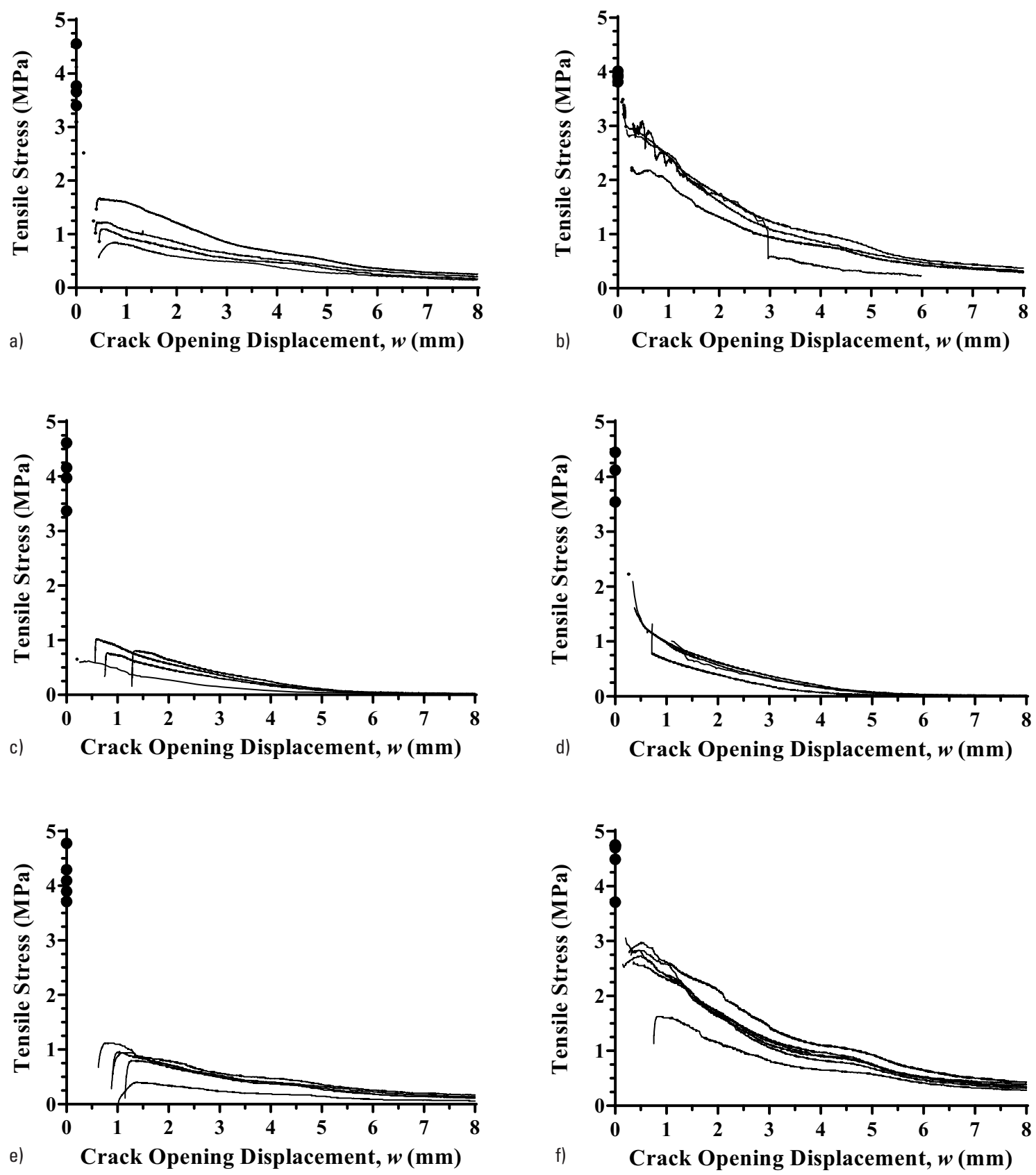

Fig. 10. Uniaxial test results: a) mix DA-0.5-EH, b) mix DA-1.0-EH, c) mix DA-0.5-S, d) mix DA-1.0-S, e) mix AM-0.4-EH, f) mix AM-0.8-EH

residual capacity of the specimens. Soon after cracking it was clear that the concrete provided no contribution to the tensile strength and that the strength was due to the fibres alone. Following the conclusion of testing of uniaxial specimens with end-hooked fibres, the number of fibres crossing the plane of the dominant crack was recorded. The results are presented in Table 3.

The experimental results for the prism bending tests are shown in Fig. 11. Three distinct phases describe the response of the three-point notched bending test: i) an elastic phase up to cracking, ii) a flexural hardening response up to peak load and iii) a reduction in load with increasing CMOD.

Before comparing the results from the inverse analysis of the bending tests, the uniaxial test data needs to be compensated for the boundary (wall) effect. The presence of a boundary restricts a fibre from being freely orientated $[23,27-30]$. An orientation factor $k_{t}$ must be applied to the uniaxial test results to remove this influence, thus converting the results to those of an equivalent 3D fibre distribution free of boundary factors. For an element approximately square in section and tested in tension, as is the case in this study, the boundary influence found in Lee et al. [30] can be approximated as follows:

$k_{t}=0.5 \leq \frac{1}{0.94+0.6 l_{f} / b} \leq 1$

It is worth noting that for the prism tests, the wall effect is largely mitigated by the influence of the notch at the bottom and compressive region at the top; in this case only the side walls provide significant influence and the wall effect can be approximated as a $2 \mathrm{D}$ problem. For the case of prism tests, provided that $l_{f} / b \leq 1$, the boundary influence factor may be adapted from the $2 \mathrm{D}$ approximation of $\mathrm{Ng}$ et al. [23] as 
Table 2. LSCT readings from uniaxial tests at $\mathrm{COD}=1.5 \mathrm{~mm}$

\begin{tabular}{|c|c|c|c|c|c|c|}
\hline Dog-bone ID & North (mm) & South (mm) & East (mm) & West (mm) & $\begin{array}{l}\text { Out-of-plane } \\
\text { rotation (rad) }\end{array}$ & $\begin{array}{l}\text { In-plane } \\
\text { rotation (rad) }\end{array}$ \\
\hline DA-0.5-EH-1 & 1.79 & 1.23 & 1.12 & 1.85 & 0.00361 & -0.00298 \\
\hline DA-0.5-EH-2 & 1.32 & 1.67 & 1.26 & 1.76 & -0.00226 & -0.00204 \\
\hline DA-0.5-EH-3 & -0.12 & 3.15 & 2.14 & 0.83 & -0.02109 & 0.00535 \\
\hline DA-0.5-EH-4 & 0.76 & - & 1.97 & 1.77 & - & 0.00082 \\
\hline DA-1.0-EH-1 & 1.41 & 1.57 & 0.51 & 2.51 & -0.00103 & -0.00816 \\
\hline DA-1.0-EH-2 & 1.50 & 1.48 & 2.12 & 0.90 & 0.00013 & 0.00498 \\
\hline DA-1.0-EH-3 & 2.37 & 0.61 & 1.12 & 1.90 & 0.01135 & -0.00318 \\
\hline DA-1.0-EH-4 & 1.62 & - & 1.40 & 1.49 & - & -0.00037 \\
\hline DA-0.5-S-1 & 0.87 & 2.10 & 1.30 & 1.74 & -0.00794 & -0.00180 \\
\hline DA-0.5-S-2 & 0.62 & 2.45 & 1.09 & 1.86 & -0.01181 & -0.00314 \\
\hline DA-0.5-S-3 & 1.59 & - & 0.87 & 2.04 & - & -0.00478 \\
\hline DA-0.5-S-4 & 0.58 & - & 2.03 & 1.92 & - & 0.00045 \\
\hline DA-1.0-S-1 & 1.40 & 1.60 & - & - & -0.00129 & - \\
\hline DA-1.0-S-2 & 0.94 & 2.08 & 1.03 & 1.96 & -0.00735 & -0.00380 \\
\hline DA-1.0-S-3 & 1.30 & 1.71 & 1.51 & 1.50 & -0.00265 & 0.00004 \\
\hline DA-1.0-S-4 & 1.50 & - & 0.91 & 2.12 & - & -0.00494 \\
\hline AM-0.4-EH-2 & 1.95 & 0.93 & 1.44 & 1.69 & 0.00658 & -0.00102 \\
\hline AM-0.4-EH-3 & 0.79 & 2.13 & 1.38 & 1.59 & -0.00864 & -0.00086 \\
\hline AM-0.4-EH-4 & 1.51 & 1.49 & 2.48 & 0.52 & 0.00013 & 0.00800 \\
\hline AM-0.4-EH-5 & 1.65 & 1.36 & 1.73 & 1.27 & 0.00187 & 0.00188 \\
\hline AM-0.4-EH-6 & 0.99 & 1.98 & 1.91 & 1.12 & -0.00639 & 0.00322 \\
\hline AM-0.8-EH-1 & 1.05 & 1.96 & 3.43 & -0.43 & -0.00587 & 0.01575 \\
\hline AM-0.8-EH-2 & 2.30 & 0.67 & 2.56 & 0.47 & 0.01052 & 0.00853 \\
\hline AM-0.8-EH-3 & 1.65 & 1.30 & 3.12 & -0.06 & 0.00226 & 0.01298 \\
\hline AM-0.8-EH-4 & 2.42 & 0.54 & 0.61 & 2.44 & 0.01213 & -0.00747 \\
\hline AM-0.8-EH-5 & 0.50 & 2.50 & 0.81 & 2.19 & -0.01290 & -0.00563 \\
\hline AM-0.8-EH-6 & 0.23 & 2.75 & 1.93 & 1.09 & -0.01626 & 0.00343 \\
\hline
\end{tabular}

$k_{b}=\frac{\pi}{3.1+0.6 l_{f} / b} \leq 1$

Applying the inverse analysis technique to a notched SFRC beam in bending described by Eqs. (12) to (14) is illustrated in Fig. 12 for $w_{T}=0.3 \mathrm{~mm}$. It can be seen that the proposed model fits well within the data obtained from the uniaxial tensile test data, compensated for the boundary effect.

\section{$5 \quad$ Simplified model for design}

In the establishment of Eqs. (7) and (10) it is assumed that sufficient cracking has occurred such that the neutral axis is sufficiently high in the section and thus the contribution of the uncracked concrete to the bending moment is small compared with that provided by the fibres. In determining a simple model we can adopt points corresponding to CMODs of 1.5 and $3.5 \mathrm{~mm}$, which correspond to points $\mathrm{CMOD}_{2}$ and $\mathrm{CMOD}_{4}$ according to [9] and shown in Fig. 13. These points are selected to be sufficiently separated from each other so as to provide reasonable modelling over the most important region of the $\sigma-w$ curve for both service and strength limit design and with point $\mathrm{CMOD}_{2}$ being sufficiently distant from initial cracking such that the contribution of the uncracked concrete to the section capacity of the prism is small [31].

Considering Eqs. (7) to (10) with a linear constitutive law interpolating between points $\mathrm{CMOD}_{2}$ and $\mathrm{CMOD}_{4}$, with $k_{1} k_{2}=1$, results in 
Table 3. Number of fibres crossing failure plane in uniaxial tests

\begin{tabular}{llll}
\hline Specimen ID & $\begin{array}{l}\text { Number } \\
\text { of fibres }\end{array}$ & Specimen ID & $\begin{array}{l}\text { Number } \\
\text { of fibres }\end{array}$ \\
\hline DA-0.5-EH-1 & 126 & AM-0.4-EH-3 & 94 \\
\hline DA-0.5-EH-2 & 162 & AM-0.4-EH-4 & 51 \\
\hline DA-0.5-EH-3 & 169 & AM-0.4-EH-5 & 86 \\
\hline DA-0.5-EH-4 & 131 & AM-0.4-EH-6 & 84 \\
\hline DA-1.0-EH-1 & 208 & AM-0.8-EH-1 & 175 \\
\hline DA-1.0-EH-2 & 228 & AM-0.8-EH-2 & 169 \\
\hline DA-1.0-EH-3 & 265 & AM-0.8-EH-3 & 158 \\
\hline DA-1.0-EH-4 & 231 & AM-0.8-EH-4 & 131 \\
\hline AM-0.4-EH-1 & 57 & AM-0.8-EH-5 & 158 \\
\hline AM-0.4-EH-2 & 79 & AM-0.8-EH-6 & 138 \\
\hline
\end{tabular}

$f_{w}=\frac{f_{R 2}}{3}+\left(f_{R 4}-f_{R 2}\right) \xi(w) \geq 0$

$\xi(w)=\frac{w}{3} \cdot \frac{\left(D-d_{n}\right)}{\left(h_{s p}-d_{n}\right)}-\frac{1}{4}$

with $f_{R 2}$ and $f_{R 4}$ calculated in accordance with EN 14651 [9] (Fig. 13) as

$f_{R, j}=\frac{3 F_{j} a}{b h_{s p}^{2}} \ldots . j=2,4$

For three-point bending, the shear span $a=l / 2$.

The model of Eqs. (18) and (19) is compared with the direct tension test data - with the boundary effect compensated for by Eq. (16) - in Fig. 14 for the domain $w \in[0$, 2.0] $\mathrm{mm}$. The prediction according to fib Model Code 2010 [10] is also plotted, with the Model Code model multiplied by factor $k_{2}$ to include the influence of the notch in
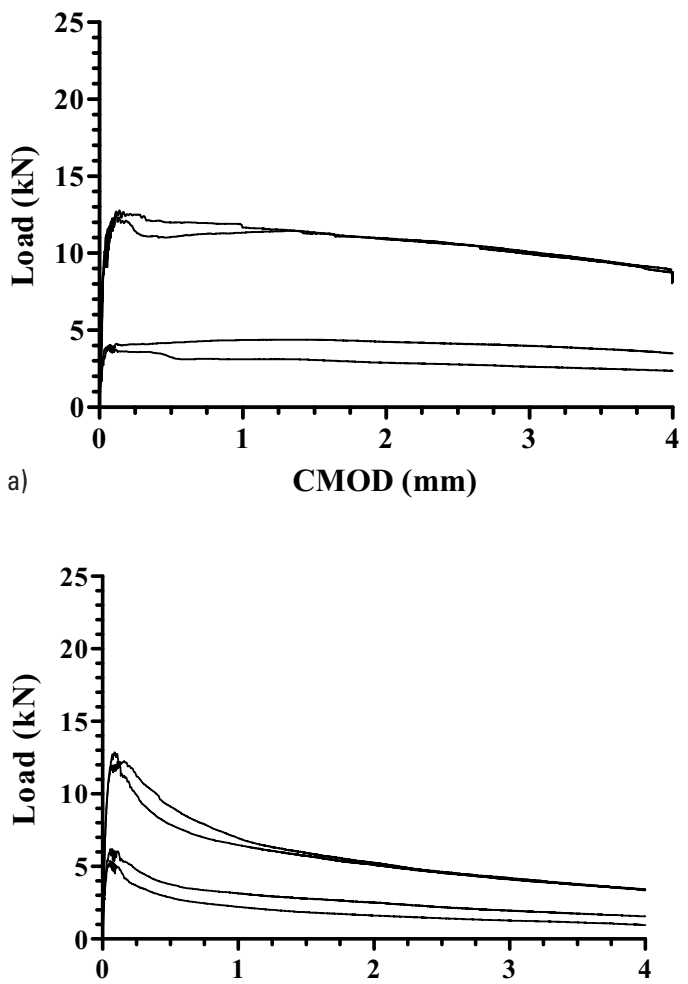

c)

CMOD (mm)

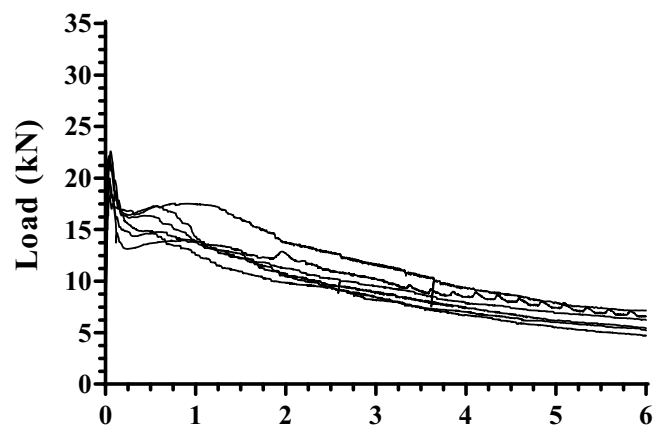

e)

CMOD (mm)
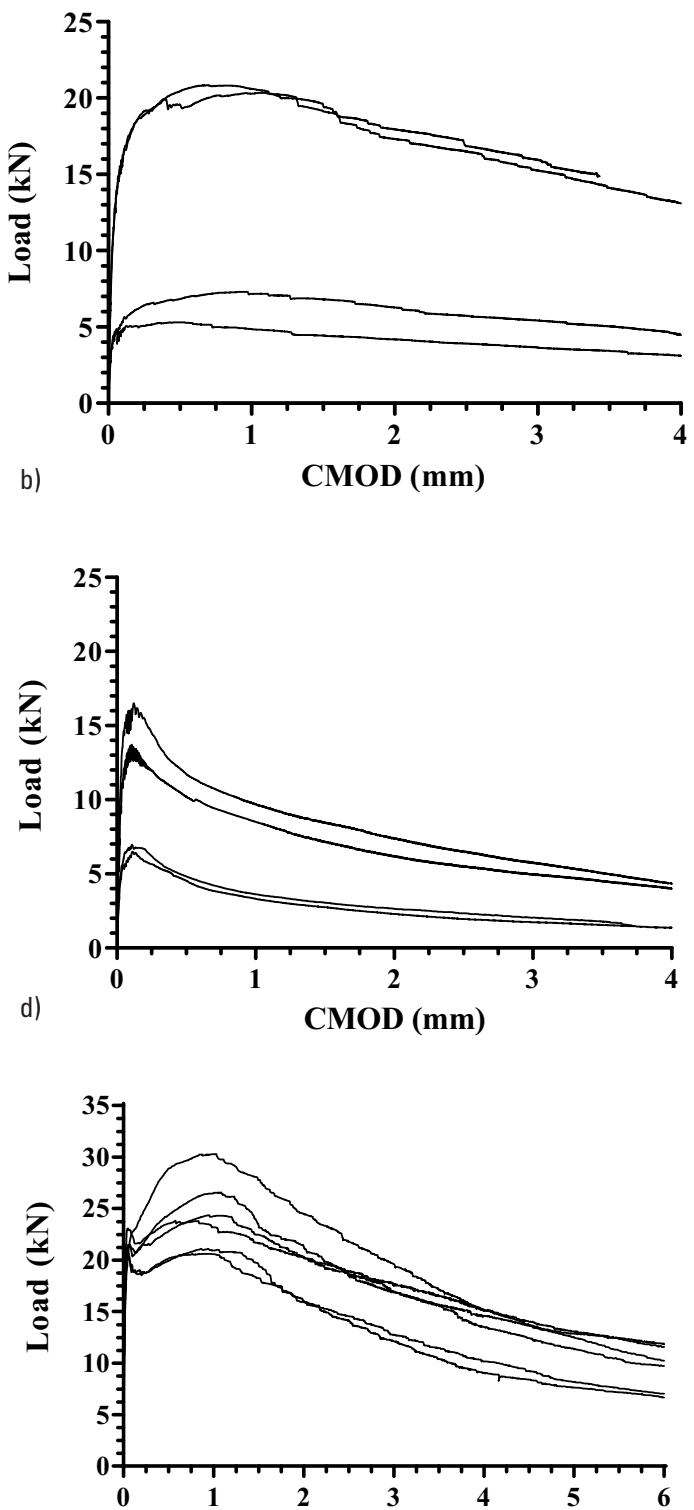

f)

CMOD (mm)

Fig. 11. Prism bending test results: a) mix DA-0.5-EH, b) mix DA-1.0-EH, c) mix DA-0.5-S/mix DA-1.0-S (higher curves 150 mm square prisms/ lower curves $100 \mathrm{~mm}$ square prisms), e) mix AM-0.4-EH, f) mix AM-0.8-EH 


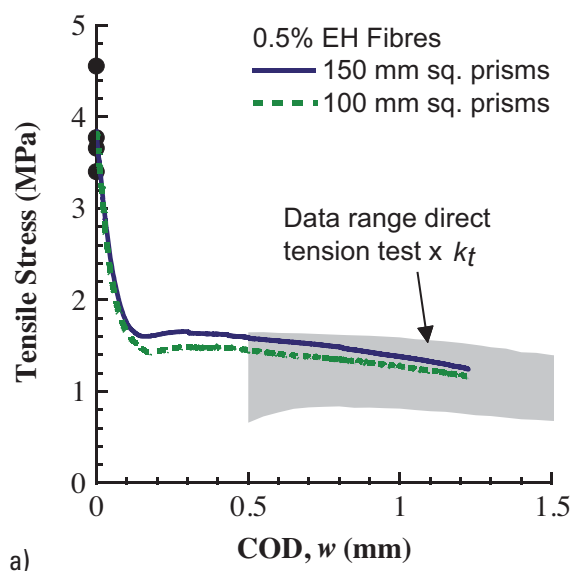

a)
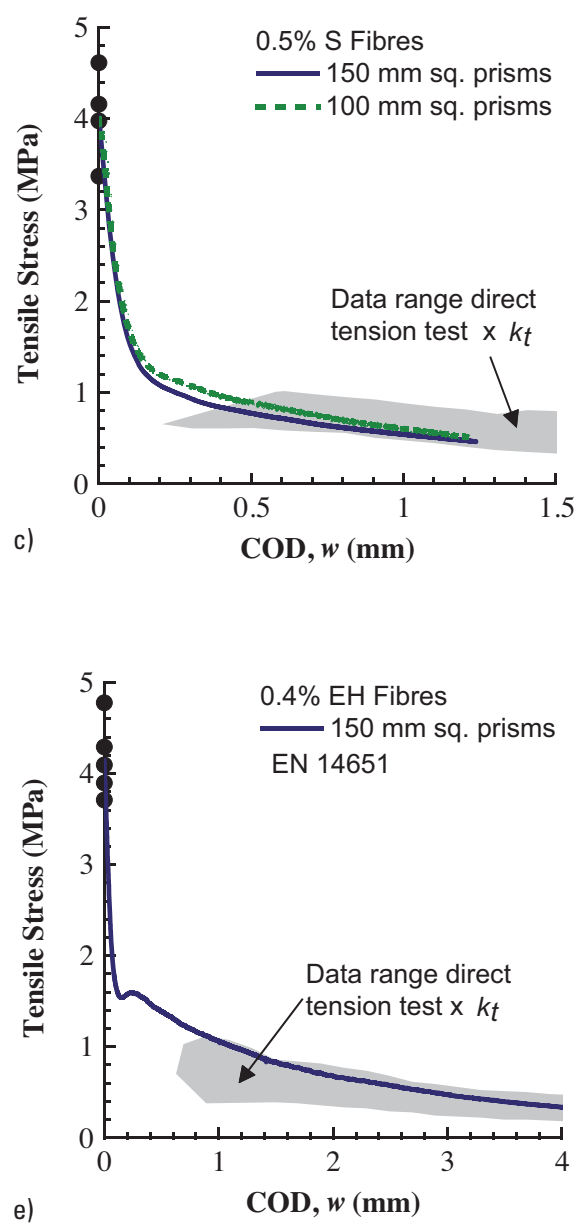
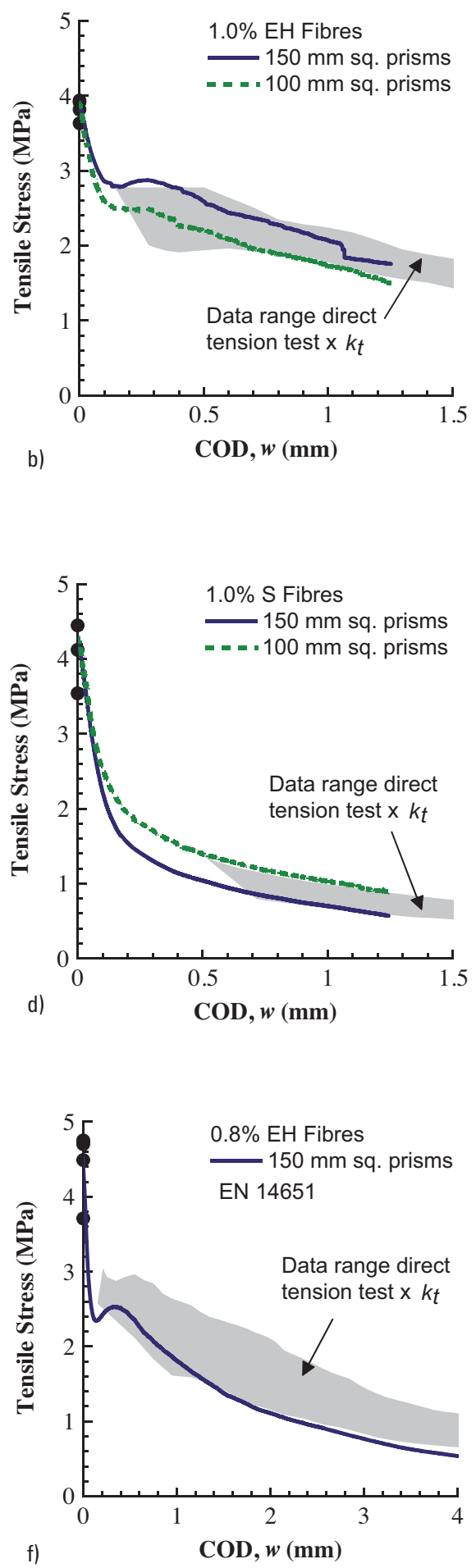

Fig. 12. Comparison of predicted uniaxial $\sigma-w$ curves obtained from inverse analysis of prism bending tests with uniaxial test data: a) mix DA-0.5-EH, b) mix DA-1.0-EH, c) mix DA-0.5-S, d) mix DA-1.0-S, e) mix AM-0.4-EH, f) mix AM-0.8-EH

the prism tests (referred to as Modified fib MC2010 in Figs. 14 and 15). The simplified model developed above compares reasonably with the tensile test data over the range $0.5 \mathrm{~mm} \leq w \leq 1.5 \mathrm{~mm}$. Beyond $1.5 \mathrm{~mm}$ the results are somewhat conservative; this could be improved by selecting a second calibration point beyond $\mathrm{CMOD}_{4}$ (i.e. > $3.5 \mathrm{~mm}$ ) on the moment versus CMOD plot. On the other hand, the fib Model Code 2010 relationship generally overestimates the tensile capacity at a given COD.

The importance of the observation above should not be underestimated. When relying on physical models to describe behaviour, e.g. shear and punching shear [32, 33], the material laws must first be accurately established.

To further validate the model, data was collated from the studies of Colombo [34] (used in di Prisco et al. [11] for comparison with fib Model Code 2010 [10] model) and Deluce [35]. In these studies, both indirect and direct tension tests were performed on SFRC produced from the same mix.

The indirect tension tests of [34] were performed on three $150 \mathrm{~mm}$ square notched prisms spanning $450 \mathrm{~mm}$ under a four-point loading configuration. The prisms had 


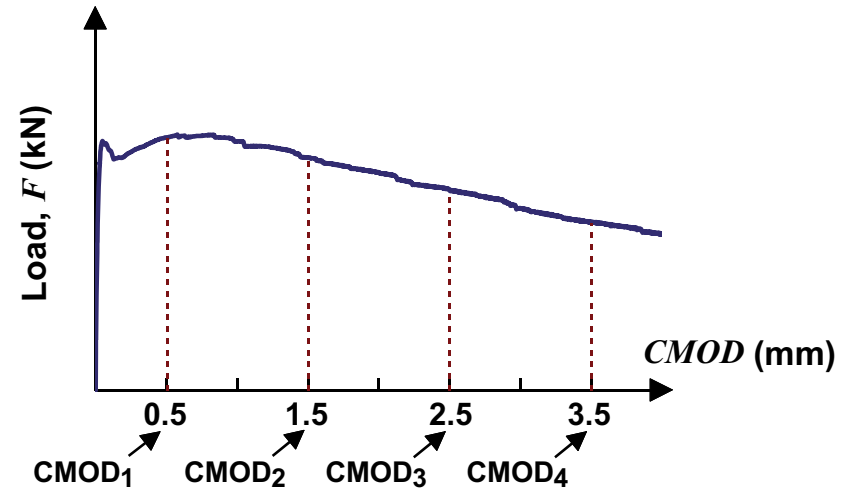

Fig. 13. Definitions of key points on the applied force versus CMOD curve for flexural testing of prisms according to fib Model Code 2010 [10] a notch depth of $45 \mathrm{~mm}$. The direct tension tests of [34] used $3 \times 75 \mathrm{~mm}$ diameter core samples taken from cast prisms and notched at mid-height; the cylinders were tested with both ends fixed to the loading platens. As the tensile specimens were obtained using cores from a larger section, the boundary influence is eliminated in this case, i.e. $k_{t}=1.0$. In addition $k_{2}=1.0$, as both the prism tests and tension tests are on notched specimens.

Deluce [35] presented the results of direct tension tests on three dog-bone specimens and a single notched prism bending test. The prism specimens spanned $456 \mathrm{~mm}$, had a cross-section of $150 \times 150 \mathrm{~mm}$ and a notch depth of $25 \mathrm{~mm}$.
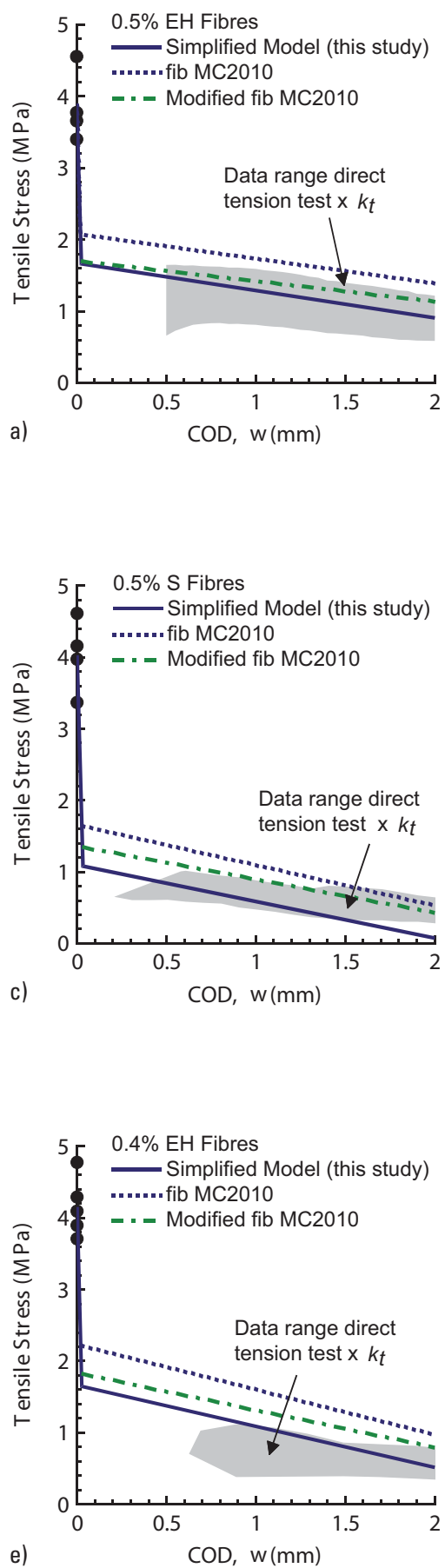
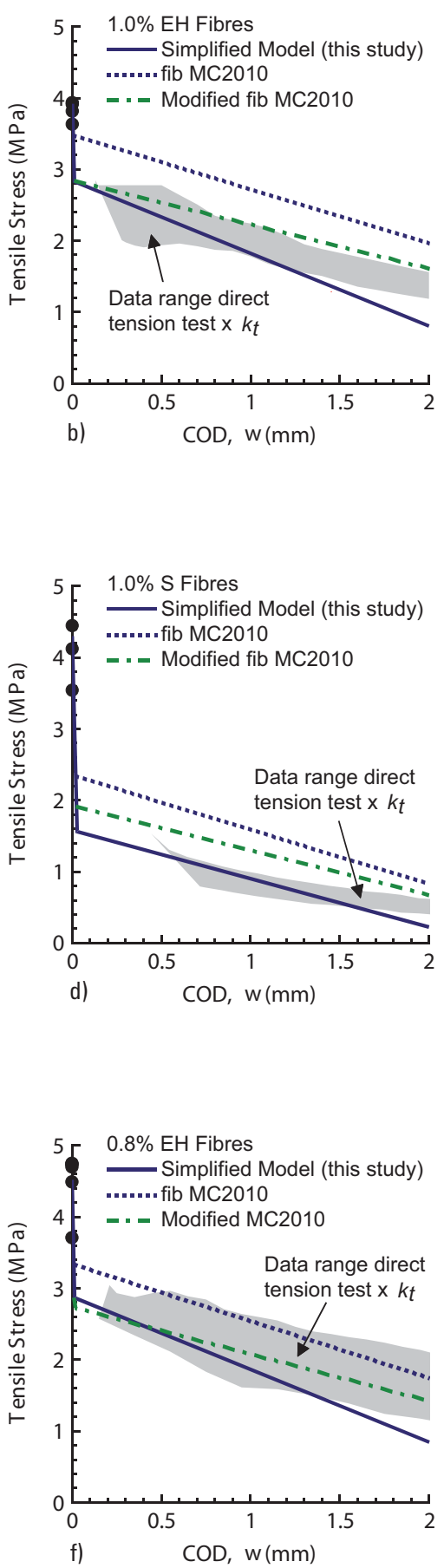

Fig. 14. Comparison of simplified design model with the uniaxial test data: a) mix DA-0.5-EH, b) mix DA-1.0-EH, c) mix DA-0.5-S, d) mix DA-1.0-S, e) mix AM-0.4-EH, f) mix AM-0.8-EH 

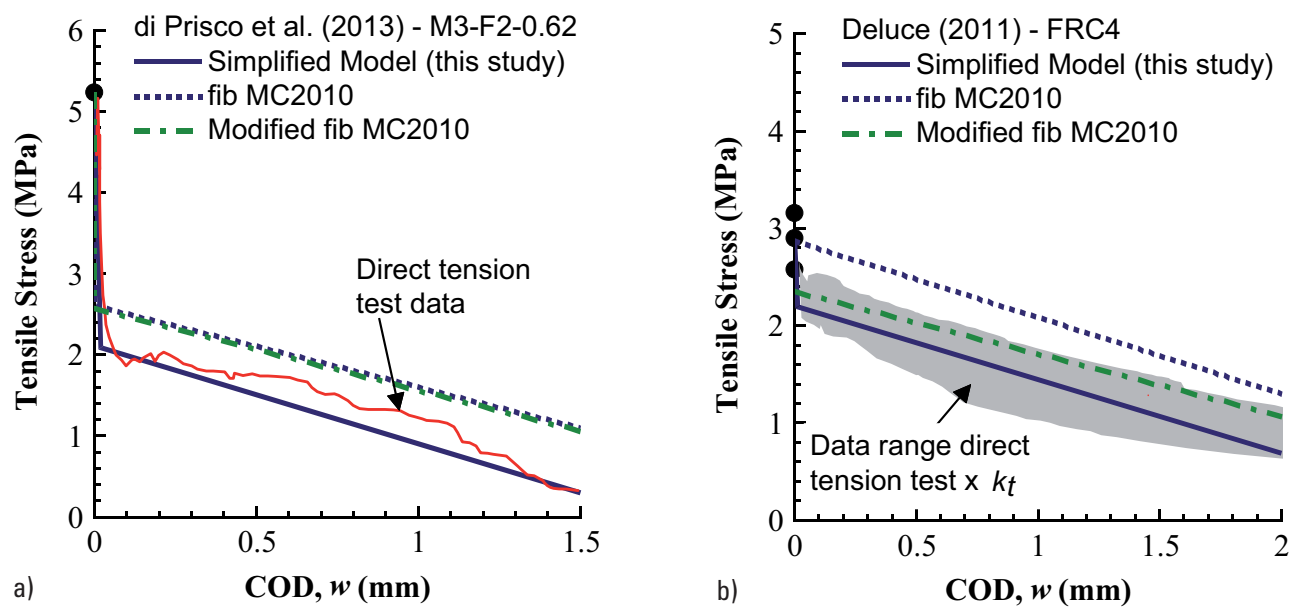

Fig. 15. Comparison of simplified design model with data obtained from: a) di Prisco et al. [11] mix M3-F2-0.62, b) Deluce [35] mix FRC4

Table 4. Comparison of residual tensile strength at crack opening displacements (COD) of 0.5 and $1.5 \mathrm{~mm}$

\begin{tabular}{|c|c|c|c|c|c|c|c|c|c|c|c|}
\hline \multirow[t]{4}{*}{ Researchers } & \multirow[t]{4}{*}{ Test } & \multicolumn{5}{|c|}{ at $w=0.5 \mathrm{~mm}$} & \multicolumn{5}{|c|}{ at $w=1.5 \mathrm{~mm}$} \\
\hline & & \multirow{3}{*}{$\begin{array}{l}\text { Exp. } \\
f_{t f}(\mathrm{MPa}) \\
-\mathrm{A}-\end{array}$} & \multicolumn{2}{|c|}{ fib model } & \multicolumn{2}{|c|}{ Proposed model } & \multirow{3}{*}{$\begin{array}{l}\text { Exp. } \\
f_{t f}(\mathrm{MPa}) \\
-\mathrm{D}-\end{array}$} & \multirow{2}{*}{\multicolumn{2}{|c|}{$\begin{array}{l}f i b \text { model } \\
f_{t f}(\mathrm{MPa})\end{array}$}} & \multicolumn{2}{|c|}{ Proposed model } \\
\hline & & & \multicolumn{2}{|c|}{$f_{t f}(\mathrm{MPa})$} & \multicolumn{2}{|c|}{$f_{t f}(\mathrm{MPa})$} & & & & $f_{t f}(\mathbf{N}$ & \\
\hline & & & $-B-$ & $\mathbf{B} / \mathbf{A}$ & $-\mathrm{C}-$ & $\mathbf{C} / \mathbf{A}$ & & $-\mathbf{E}-$ & E/D & $-\mathbf{F}-$ & F/D \\
\hline Colombo [34] & M3-F2-0.62 & 1.74 & 2.12 & 1.22 & 1.52 & 0.87 & 0.33 & 1.12 & 3.39 & 0.30 & 0.91 \\
\hline Deluce [35] & FRC1 & 1.85 & 3.53 & 1.91 & 2.63 & 1.42 & 1.23 & 2.56 & 2.08 & 1.66 & 1.35 \\
\hline & FRC2 & 2.52 & 3.94 & 1.56 & 3.36 & 1.33 & 1.98 & 3.22 & 1.63 & 2.29 & 1.16 \\
\hline & FRC3 & 2.85 & 2.99 & 1.05 & 2.47 & 0.87 & 2.10 & 2.39 & 1.14 & 1.66 & 0.79 \\
\hline & FRC4 & 1.89 & 2.56 & 1.35 & 1.83 & 0.97 & 1.23 & 1.73 & 1.41 & 1.07 & 0.87 \\
\hline & FRC5 & 1.87 & 3.04 & 1.63 & 2.27 & 1.21 & 1.31 & 2.25 & 1.72 & 1.37 & 1.05 \\
\hline This study & DA-0.5-EH & 1.15 & 1.92 & 1.67 & 1.64 & 1.43 & 0.97 & 1.57 & 1.62 & 1.24 & 1.28 \\
\hline & DA-1.0-EH & 2.44 & 3.11 & 1.27 & 2.59 & 1.06 & 1.70 & 2.36 & 1.39 & 1.53 & 0.90 \\
\hline & DA-0.5-S & 0.60 & 1.39 & 2.32 & 0.94 & 1.57 & 0.60 & 0.82 & 1.37 & 0.40 & 0.67 \\
\hline & DA-1.0-S & 1.39 & 1.98 & 1.42 & 1.38 & 0.99 & 0.67 & 1.22 & 1.82 & 0.67 & 1.00 \\
\hline & AM-0.4-EH & - & 1.93 & - & 1.38 & - & 0.74 & 1.30 & 1.76 & 0.80 & 1.08 \\
\hline & AM-0.8-EH & 2.78 & 2.95 & 1.06 & 2.63 & 0.95 & 1.97 & 2.15 & 1.09 & 1.54 & 0.78 \\
\hline Mean & & & & 1.50 & & 1.15 & & & 1.70 & & 0.99 \\
\hline $\mathrm{COV}$ & & & & 0.25 & & 0.22 & & & 0.36 & & 0.21 \\
\hline
\end{tabular}

The predictions of the simplified model as given Eq. (18) are compared with the results for the Colombo [34] data in Fig. 15a, the Deluce [35] mix FRC4 in Fig. 15b and for all data, at the key points $w=0.5 \mathrm{~mm}$ and $w=$ $1.5 \mathrm{~mm}$, in Table 4. The predictions of fib Model Code $2010[10]$ are also provided. It can be seen that the simplified model proposed predicts the residual tensile strength of SFRC concrete consistently, whereas fib Model Code $2010[10]$ consistently overestimates the capacity.

\section{Discussion of the simplified model}

It is important to recognize that the philosophy adopted in fib Model Code 2010 for predicting the tensile strength is a sound one and, indeed, the simplified model presented here is adapted from that model. The key difficulty in the fib Model Code 2010 approach can be attributed to two conditions. The first is the adoption of $\mathrm{CMOD}_{1}$, corresponding to a crack mouth opening displacement of $0.5 \mathrm{~mm}$, as the first key sampling point. Adjusting for the depth of the notch, this leads to an average crack width of about $0.2 \mathrm{~mm}$; at this crack width the tensile strength of the cementitious matrix remains a significant contributor to the flexural resistance of the member. Moving this first sampling point back to $\mathrm{CMOD}_{2}(\mathrm{CMOD}=1.5 \mathrm{~mm})$ corrects this. Similarly, $\mathrm{CMOD}_{4}$ is adopted, rather than $\mathrm{CMOD}_{3}$, to maximize the distance between the first and second key points and increase the reliability of the ap- 
proach. The second condition is the influence of testing on notched specimens, where the failure section is defined by the location of the notch and not by probabilities related to fibre distributions and scatter. When tested against the available data collected in this study and elsewhere, at the key point $w=1.5 \mathrm{~mm}$ (Table 4), the model prediction to experimental ratio is 0.99 and has a COV of 0.21 .

\section{Conclusions}

In order to increase the utilization of SFRC in structural applications, it is important to establish the post-cracking, or residual, tensile strength of SFRC correctly. The postcracking behaviour of SFRC can be obtained directly from uniaxial tensile tests or indirectly, following an inverse analysis of notched beams in bending. Consequently, reliable methods to attain these results are required.

Following an experimental investigation of six softening SFRC mixes and a subsequent analysis that examined the applicability of inverse analysis techniques found in the literature, i.e. ones that led to the approach adopted in fib Model Code 2010 [10], it was found that the fib Model Code 2010 results might overestimate the residual tensile strength that forms the basis of physical models for SFRC.

To address this, a simple yet effective inverse analysis procedure was derived to find the $\sigma-w$ relationship for SFRC from prism bending tests. The model considers the influence of fibres on the moment carried by the specimen from the point in the test where the uncracked concrete has little influence on its capacity and considers rigid body rotations.

In the development of the model it is important to note that the measurement point for the CMOD is not at the notch root (i.e. the location of the true crack mouth) but at a certain distance from it. Using this observation, a rational model is derived which is independent of specimen geometry, testing span and method of testing, i.e. three- or four-point bending.

The model was validated against experimental data obtained from direct tension tests on six SFRC mixes carried out in this study and six SFRC mixes obtained from results presented in the literature. For all 12 mixes tested, each of varying fibre type and dosage, and for five different prism geometries tested, the model predicted the results well and generally within the range of scatter of the collected data.

\section{References}

1. Romualdi, J. P., Batson. G. B.: Behaviour of reinforced concrete beams with closely spaced reinforcement. Proc., ACI Journal, 60 (6), 1963, pp. 775-789.

2. van Mier, J. G. M.: Concrete Fracture: a Multiscale Approach. CRC Press, Boca Raton, Florida, USA, 2013.

3. van Vliet, M. R. A., van Mier, J. G. M.: Effect of strain gradients on the size effect of concrete in uniaxial tension. International Journal of Fracture, 95, 1999, pp. 195-219.

4. van Mier, J. G. M., van Vliet, M. R. A.: Uniaxial tension test for the determination of fracture parameters of concrete: state of the art. Engineering Fracture Mechanics, 69, 2002, pp. $235-247$.
5. Zhang, J., Stang. H.: Application of stress crack width relationship in predicting the flexural behavior of fiber reinforced concrete. Journal of Cement and Concrete Research, 28 (3), 1998, pp. 439-452.

6. Planas, J., Guinea, G. V., Elices, M.: Size effect and inverse analysis in concrete fracture. International Journal of Fracture, 95, 1999, pp. 367-378.

7. de Oliveira e Sousa, J. L. A., Gettu, R., Barragán, B. E.: Inverse analysis of the notched beam response for determining the $\sigma$-w curve for plain and fiber reinforced concretes. Anales de Mecánica de la Fractura, 19, 2002, pp. 393-398.

8. di Prisco, M., Plizzari, G., Vandewalle, L.: Fibre reinforced concrete: new design perspectives. Materials and Structures, 42, 2009, pp. 1261-1281.

9. EN 14651:2007: Test Method for Metallic Fibre Concrete Measuring the Flexural Tensile Strength (Limit of Proportionality (LOP), Residual). European Committee for Standardization.

10. fib - International Federation for Structural Concrete. fib Model Code for Concrete Structures 2010. Berlin: Verlag Ernst \& Sohn, 2013.

11. di Prisco, M., Colombo, M., Dozio, D. (2013): Fibre-reinforced concrete in fib Model Code 2010: principles, models and test validation. Structural Concrete, 14, pp. 342-361.

12. Zhu, Y.: The Flexural Strength Function for Concrete Beams: A Closed Form Solution Based on the Fictitious Crack Model. Bulletin No. 157, Department of Structural Mechanics \& Engineering, The Royal Institute of Technology, Stockholm, Sweden, 1991, pp. B2-B23.

13. Sigrist, $V$.: Zum Verformungsvermögen von Stahlbetonträgern (On the Deformation Capacity of Reinforced Concrete Beams). PhD dissertation, IBK Report No.210, Swiss Federal Institute of Technology, Switzerland, 1995 (in German).

14. Foster, S. J, Htut, T. N. S., Ng, T. S.: High Performance Fibre Reinforced Concrete: Fundamental Behaviour and Modelling. Proc. of 8th Int. Conf. on Fracture Mechanics Concrete and Concrete Structures (FraMCoS-8), Toledo, Spain, 10-14 Mar 2013, pp. 69-78.

15. Htut, T. N. S.: Fracture processes in steel fibre reinforced concrete. PhD dissertation, School of Civil \& Environmental Engineering, The University of New South Wales, Australia, 2010.

16. JCI-S-002-2003: Method of test for load-displacement curve of fiber reinforced concrete by use of notched beam. Japan Concrete Institute, 2003

17. Voo, J. Y. L., Foster, S. J.: Tensile fracture of fibre reinforced concrete: variable engagement model. In: di Prisco, M., Felicett, R. Plizzari, G.A. (eds.), 6th Rilem Symposium on Fibre-reinforced Concrete (FRC), Varenna, Italy, 20-22 Sept 2004, pp. 875-884.

18. Foster, S. J., Voo, Y. L. Chong, K. T.: Analysis of Steel Fiber Reinforced Concrete Beams Failing in Shear: Variable Engagement Model, chap. 5: Finite Element Analysis of Reinforced Concrete Structures, Lowes, L., Filippou, F. (eds.), ACI SP-237, 2006, pp. 55-70 (CD-ROM).

19. Voo, Y. L., Foster, S. J.: Reactive powder concrete: analysis and design of RPC girders. Lambert Academic Publishing, 2009, ISBN 978-3-8383-2406-7.

20. Lee, G. G., Foster, S. J.: Behaviour of steel fibre reinforced mortar III: variable engagement model II. UNICIV report R448, School of Civil \& Environmental Engineering, The University of New South Wales, Australia, 2007.

21. Lee, G. G., Foster, S. J.: Modelling of shear-fracture of fibrereinforced concrete. Int. fib Symposium, CRC Press, 2008, pp. 493-499.

22. Voo, J. Y. L., Foster, S. J.: Variable engagement model for fibre-reinforced concrete in tension. UNICIV report R-420, 
School of Civil \& Environmental Engineering, The University of New South Wales, Australia, 2003.

23. Ng, T. S., Htut, T. N. S., Foster, S. J.: Fracture of steel fibre-reinforced concrete - the unified variable engagement model. UNICIV report R-460, School of Civil \& Environmental Engineering, The University of New South Wales, Australia, 2012.

24. AS1012.9: Methods of Testing Concrete - Determination of the compressive strength of concrete specimens. Standards Australia, 1999.

25. AS1012.17: Methods of Testing Concrete - Determination of the static chord modulus of elasticity and Poisson's ratio of concrete specimens. Standards Australia, 1997.

26. van Vliet, M. R. A.: Size effect in tensile fracture of concrete and rock. PhD dissertation, Delft University, The Netherlands, 2000.

27. Romualdi, J. P., Mandel, J. A.: Tensile strength of concrete affected by uniformly distributed and closely spaced short length wire reinforcement. Journal of American Concrete Institute Proc., 61 (6), 1964, pp. 657-671.

28. Aveston, J., Kelly, A.: Theory of multiple fracture of fibrous composites. Journal of Materials Science, 8 (3), 1973, pp. 352-362.

29. Stroeven, P.: Stereological principles of spatial modelling applied to steel fibre-reinforced concrete in tension. ACI Materials Journal, 106 (3), 2009, pp. 213-222.

30. Lee, S. C., Cho, J., Vecchio, F. J.: Diverse embedment model for steel fibre-reinforced concrete in tension: model development. ACI Materials Journal, 108 (5), 2011, pp. 516-525.

31. Amin, A., Foster, S. J., Muttoni, A.: Evaluation of The Tensile Strength of SFRC as derived from Inverse Analysis of Notched Bending Test. Proc. of 8th Int. Conf. on Fracture Mechanics Concrete \& Concrete Structures (FraMCoS-8), Toledo, Spain, 10-14 Mar 2013, pp. 1049-1057.

32. Foster, S. J.: Design of FRC Beams for Shear using the VEM and the Draft Model Code Approach, chapter 12: Recent Developments on Shear and Punching Shear on RC and FRC Elements, Minelli, F., Plizzari, G. (eds.), fib Bulletin 57, Fédération Internationale du Béton, Lausanne, Switzerland, 2010.

33. Maya, L. F., Fernández Ruiz, M., Muttoni, A., Foster, S. J.: Punching shear strength of steel fibre-reinforced concrete slabs. Engineering Structures, 40, 2012, pp. 83-94.

34. Colombo, M.: FRC Bending Behaviour: a Damage Model for High Temperatures. PhD dissertation, Politecnico di Milano, Italy, 2006.

35. Deluce, J.: Cracking Behaviour of Steel Fibre-reinforced Concrete Containing Conventional Steel Reinforcement. MASc dissertation, The University of Toronto, Canada, 2011.
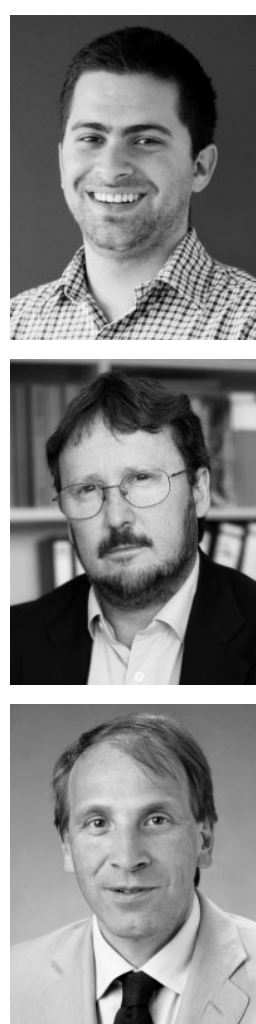

Ali Amin, Research Student Centre for Infrastructure Engineering \& Safety School of Civil \& Environmental Engineering The University of New South Wales Sydney NSW 2052, Australia Ali.Amin@unsw.edu.au

Stephen J. Foster, Professor, Head of School Civil \& Environmental Engineering The University of New South Wales Sydney NSW 2052, Australia Phone +61293855059

S.Foster@unsw.edu.au

Aurelio Muttoni, Professor School of Architecture Civil \& Environmental Engineering École Polytechnique Fédérale de Lausanne, CH-1015 Lausanne, Switzerland 